\title{
Towards ‘Creative Media Literacy’
}

\section{Steve Connolly and Mark Readman}

In this chapter, perhaps counterintuitively, we begin by challenging the orthodoxies of two key terms in media education (creativity and literacy) and then suggest that by bringing them together in a new way we can provide a framework for media production work that is critical, reflective and student-centred. We understand that production work takes place in a variety of educational contexts, some of which are explicitly vocational, but we suggest here that, if claims for production work are to be made as part of a wider project of literacy, some of the assumptions about the affordances of such work must be addressed and subjected to scrutiny. We propose, ultimately, the concept of 'creative literacy' - a critically oriented set of attributes with which students practise a systematic interrogation of their own productive processes and the meanings attributed to them. Through a philosophically grounded critical framework and examples of pedagogic practice drawn from a three year study of student production work we show how creative literacy can be recognised, developed and how the conditions of possibility for its emergence may be created.

First though, we attempt to model the kind of interrogation of terminology that we believe to be necessary for a philosophical approach to media production work. We question, initially, the assumptions around the notion of literacy, and then the myths and contradictions underpinning 'creativity'. By doing this we establish some reasonably secure foundations for our term 'creative literacy' ${ }^{1}$. We move on to outlining a conceptual framework for creative literacy - one refined through an engagement with the debates around practice based research in the arts - and then show, through discussion of concrete examples, how creative literacy might be recognised in practice. Finally we suggest the conditions that should obtain in order for creative literacy to be fostered.

\footnotetext{
${ }^{1}$ We are not the first to use this term, but Woods (2001) uses it to refer specifically to reading as empowerment, therapy and pleasure.
} 


\section{Media Literacy in context}

An examination of literacy and creativity highlights some of the differences between the field of media education in the UK - where we both work - and the wider global field of media literacy. In the UK, the formalising of a media education agenda through public examinations and, historically, some media elements in various versions of the National Curriculum may seem like some kind of educational 'promised land' to those teachers in countries who are either struggling to get policy makers to see the significance of this kind of educational discourse, or working in places where media education is subsumed into wider political discourse about literacy, internet safety or business and commerce. In, the USA, for example, the media literacy movement seems to sit quite comfortably in a place where it can be seen as a way of improving overall educational outcomes, allowing students in both schools and universities to use their developing skills in digital media and knowledge of texts to access a range of other learning opportunities. This idea is less developed in the UK, where media educators are specialist teachers preparing students for quite specialised examinations in film and media. Whilst this level of specialism may appeal to school teachers outside the UK, it brings with it its own peculiar set of problems. As media education is assessed through a national examination system which asks students to complete both practical and theoretical tasks in Media Studies and Film Studies, in some ways, it becomes ever narrower, with teachers tending to 'teach to the test' or to the coursework production task and often ignoring the bigger picture that a Media literacy approach might allow for.

Throwing creativity - particularly a policy-endorsed version of it, into this mix also creates a number of problems for teachers, both locally and globally. For a number of years in the first decade of the $21^{\text {st }}$ century, the promotion of creativity was a governmental priority in the UK, with large sums of money being put into both schools and educational projects which sought to develop various areas of creative effort. Media Studies courses were an obvious focus for this promotional activity, with Media departments in schools and colleges receiving a lot of attention, both in financial terms and in the sense that they were good places for schools to 'show off' their ability to meet the requirements of this creativity agenda. Coupled with the Labour government's expansion of the specialist schools programme - in which 
schools were funded, at least partly, with a view to develop community programmes which involved the school spreading their expertise in areas such as creativity - this turning of the spotlight on to Media education, amongst other creative subject areas, added new pressures on to teachers of Media and Film. Firstly, there was the pressure to demonstrate that these additional monies were being spent wisely; secondly, there was the problem that any intra-school focus on creativity and more specifically on Media Studies was likely to create ill-feeling on the part of colleagues in other subjects and areas where there was traditionally less focus on creativity, (e.g. mathematics). Finally, the rather scattergun approach to promoting creativity in this period, characterised by an almost 'anything goes' attitude meant that while many projects were worthwhile and improved learning, a good many others did not. A fuller explanation of these particular problems is given by Connolly (Connolly, 2013a), but it should suffice to say that the relationship between Media Education and creativity in this time was particularly complex. Subsequent changes of government in the UK have lessened the emphasis on creativity (or rather refocused it, so that it is seen as something that arises out of particular types of knowledge, rather than underpinning knowledge) and turned attention back to traditional educational disciplines and an emphasis on rote learning. Nevertheless there remains what Cannon describes as

.... a traverse between cultures of technocratic and functional ideology at one end of the spectrum, in tension with rhetorical appeals to harnessing one's creative potential and fulfilling personal dreams at the other. (2016, p.50)

Our attempt to frame a creative literacy sits in this context - an attempt to avoid instrumentalising production work, to embrace its complexity, and to advocate the necessity of a critical relationship with it that goes beyond 'inoculation' and protectionism. We move on to identifying some specific issues around first literacy, then creativity, identifying what is both problematic and troublesome.

\section{The Problem of Literacy}

For media education as a whole, literacy is a deeply problematic term. The longestablished connection between print media texts and other non-print texts that has 
been explored through the school or college based discipline of "Media Studies" has led to the assumption that there must be some kind of inherent connection between the literacies that people demonstrate when they read books and those literacies that they demonstrate when they watch a film or play a video game. This kind of connection is actually quite contentious- a point argued, by amongst others, David Buckingham who proposes that what is often termed "media literacies" frequently challenges the dominance of traditional modes of communication (Buckingham, 2003), but most theorists (Burn and Durran, 2007; Bruce, 2002), practitioners, and students would agree that there are parallels between the reading and writing of print text and the reading and creation of other kinds of non-print, moving image and digital text.

We have explored these problematic parallels as they appear in creative media production work before (Connolly, 2008), noting that there are some connections between the framework used to teach the moving image in schools and certain features of languages. In this work, it was argued that creative production work allowed students to learn and interrogate both the language of the text itself (how it communicates with its audience) and the metalanguage used to describe that communication. This notion of moving image production work as a means of becoming literate in the moving image was not one that sat entirely comfortably for either the author or teachers of media more broadly, requiring, as it did to ignore some of the more obvious practical problems of this analogy (What for example, could one say about acting? An essential element to many moving image texts, it was very difficult to draw a parallel between this and any particular linguistic feature, unlike something such as editing, which was more obviously analogous to something like punctuation). This complexity means that the connection between production work in media education and literacy is perhaps not as clear cut as it needs to be in order to establish the former as an integral aspect of the latter.

The term "multiliteracies" (Cope and Kalantzis, 2000) has been put forward as one way of addressing the problem that Burn and Durran(2007) identify for notions of

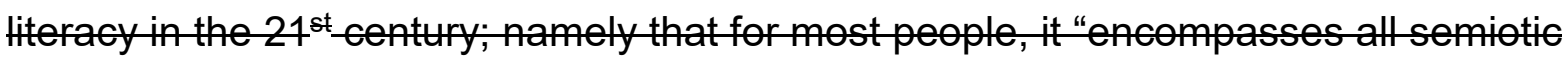
modes" rather than simply reading and writing. It also allows room for the possibility that new digital technologies can be used to strengthen traditional forms of literacy 
such as writing and oral storytelling (Ong, 1982; Jenkins 2008) and retains the sense that literacy is about making or producing texts as it is about reading them.

There is also the sense that in wider society, the word "literacy" is being used as a kind of shibboleth; as an indicator that in a particular area of human activity, there is some kind of societal inadequacy that needs to be addressed through a particular course of education. Using the word in conjunction with this perceived area of inadequacy seems to imply a deficit model of learning, which in turn suggests that the person or persons using the term believes that something "needs to be done" about human behaviour. "Financial literacy", "computer literacy", "moral literacy" and "faith literacy are all terms that have obtained currency in public discourse in recent years because they reflect the idea, put forward by Hoechsmann and Poyntz (2012) that by attaching the notion of literacy to a given area of activity, one is suggesting a "lowest common denominator of participation" that is expected of the people doing that activity and that people's competency in it, is what we as a society would normally expect. Interestingly, such uses of the word literacy often generate debate about what kind of attributes are required for such competency - something that we propose being clear about when it comes to our own use of the term literacy below.

It is with some caution then, that we look to use the word literacy in relation to the way that creative practice in media education might be discussed, but we retain it as a term that refers to communication across a range of modes; a sense of producing texts as well as reading them; the idea of a set of attributes which mark out competency in communication; and as something social that connects us to other human beings.

\section{The Trouble with Creativity}

The term 'creativity' is also freighted with contradictions, and one often used by students, parents, teachers and policymakers when describing the desirable outcomes and opportunities afforded by media education and media literacy. Despite attempts to fix it and operationalise it in policy and practice, however, it remains a problematic term, used in often incoherent and contradictory ways. It's worth taking some time to look at just a few of the contradictions in order to make it clear that when we use the term creative literacy we are not indulging any of the romantic 
connotations of 'creativity'. As an adjective, rather than a noun, the term 'creative' may be used to delineate a disciplinary area and, following Hesmondhalgh (2007), to refer to activities of 'symbol creation'. But given the close relationship between the noun and the adjective it is necessary to establish some critical distance here; as a modifier, we suggest that the word 'creative' has some utility in the field of media education - and for us to refer to a field of activity - but first we discuss the contradictions inherent in the noun.

The problems are evident in all discourses which contain (or, as we suggest, produce) creativity: the importance of novelty/innovation; the determination of 'value'; and the relationship between the descriptive term and the nature of the activities categorised thus. It is one of our fundamental contentions that 'creativity' is not, and cannot be, merely a descriptive term because it is a concept and, therefore, when it is applied and used it is always implicitly theorised. And what is particularly intriguing about it as a concept, particularly within education, is that it is able to attach itself to different interests with a high degree of promiscuity; it is simultaneously bereft of and rich in meaning. Yet, despite its instability there are many documents and practices which claim to have secured the term for the purposes of, promoting, implementing or assessing it.

Readman (2011) has argued that creativity is always a product of language and social practice and, therefore, not a 'thing' that can be discovered, analysed and measured. His analysis of specific UK education policy documents, which focus on creativity, reveals how acts of classification are performed which limit and translate this abstract concept into practices and activities that are amenable to inspection. The policy rhetoric produces an educationally legitimate version of creativity, and shifts from illustration to prescription, whilst continuing to retain a claim to some kind of universal notion of creativity. In doing so it illustrates one of the central tensions in the concept - that between inclusive/democratic notions of creativity, and exclusive/elitist notions of creativity.

The ideologically rich notion that some people are simply 'special' is an enduring one; even Boden (1992; 1999), whose work seeks to demystify creativity through "computational psychology" reinforces the ideology of the extraordinary individual here with regard to "motivation, emotional involvement, and self-confidence": 
Thus, we see a characteristic personality type of highly creative individuals, many of whom are driven, and in turn drive their associates even unto death: Florence Nightingale, lying on her sickbed, dictated (in both senses) to her male helpers, some of whom sickened and died under the strain. (Boden 1999, p.352)

This elitist model of creativity, however, is in continual tension with more democratic expressions of creative possibilities. Ken Robinson, for example, argues that creativity is a universal social asset that must be harnessed:

We all have creative abilities and we all have them differently. Creativity is not a single aspect of intelligence that only emerges in particular activities, in the arts for example. It is a systemic function of intelligence that can emerge wherever our intelligence is engaged. (Robinson, 2001, p.12)

One response to the 'creativity problem' (that is, the problem of having a single term which is applied to an enormous diversity of activities, processes and outcomes) is to implement a qualitative differentiation. Craft (2001), for example, differentiates between 'big C' and 'little c' creativity:

'Little c creativity' is distinct from 'high creativity', which I take to mean the extraordinary creativity of the genius, in any particular field such as science, art, dance, mathematics, etc...The admission of new creative minds into a domain by the field is the recognition of the potential of 'big C creativity'; in other words, of the kind of creativity which actually changes the domain, they refashion it. (Craft, 2001, p.46)

Craft's 'little c creativity' represents an attempt to recruit a range of disparate activities under the seductive and powerful unity of 'creativity' - at their simplest, these include positive strategies for coping with life - and this, therefore, reveals a philosophical problem with categorising and understanding the concept.

In case this appears to be mere sophistry, let's consider for a moment the issues raised when creativity is related to the concept of craft. Nelmes, for example, seems to express frustration with the terms when she repeatedly asks versions of the question: "...to what extent is the screenplay a creative form, to what extent is it a form based on craft and can craft and creativity be separated?" (2007, pp.108-109). Nelmes' argument depends upon an idea of difference between craft and creativity in 
order to suggest that the screenplay represents a synthesis of these two qualities. She aligns creativity with art, originality, individuality, inspiration, talent and passion, whereas craft is aligned with experience, formulae, collaboration and reiteration. Creativity is delineated as something that precedes craft: "Creativity may be essential in writing an original screenplay but, even if the writer has the greatest story idea, without craft he or she cannot express the story in terms of a screenplay" (2007, p.112). This is a persuasive argument, but it contributes to an idea of creativity as something elusive and magical which exists in a non-material realm, but which is inferred through the materiality of the screenplay. There is also the implication that the process of crafting the screenplay is not, on its own, creative, but some kind of routine (albeit disciplined) process.

Although an enormous amount of exciting, valuable and challenging work is produced under the banner of 'creativity', there is a sense that the term itself is too contradictory and too freighted with fantasies of artistic production to be sustainable as an unproblematic term of reference within an educational context. Even if one were reluctant to lose the word, it would be remiss to fail to acknowledge the ease with which it is accommodated by a neoliberal agenda (McRobbie, 2016) and, therefore, too promiscuous to retain without contestation. We have both grappled with the term in different ways (Readman, 2009, 2010, 2011, 2013; Connolly, 2014), and suggest here that to indulge, without critique, an 'ontology of creativity' would be antithetical to the project we propose. We argue then, that an interrogation of 'creativity' (such as we conduct above) is a step towards creative literacy - a reflexive and reflective state in which even treasured concepts are subject to scrutiny. Creative literacy becomes, then, a philosophical orientation towards creative practice.

We now move on to outlining a conceptual framework for creative literacy, drawing on arguments in practice based research in the arts, before progressing to a discussion of how this may be implemented.

\section{A conceptual framework for Creative Literacy}


Media production work, at all levels, continues to be a site of conflict; questions are asked, for example, about intention, technical skill and ability to operate with tonal consistency. Assertions are made about storytelling, aptitude and evidence of research. Often there are disagreements about the degree of understanding that may be inferred from a student's work:

"Practical work which is 'well-constructed', is 'stylistically appropriate' and has some kind of 'wit', is read as expressing the understanding of the student - it supposedly embodies implicit or 'tacit' knowledge, which may often be missing from the exegetical, analytical work which accompanies it." (Readman, 2013, p.168).

This is, essentially, an epistemological question - a basis for establishing knowledge about students' understanding has been sought - in other words we ask "how can we know what they know?" Even the apparently easier question of "how can we know what they can do?" has some attendant difficulties, not only due to collaborative situations, but because 'doing' requires 'thinking'.

One strategy, historically, has been to require some form of exegesis to accompany practical work - a commentary or analysis in which the student writes about what they were trying to do, what theories underpinned it and whether or not there was a successful outcome. This kind of writing about practice tends to reflect a process that begins with theory (for example, about genre, narrative, or representation), that progresses to implementation (a piece of work that engages with the theory in some way), and finally evaluates the outcome. The process has been criticised; Buckingham, for example suggests that "rather than simply 'doing the theory' first and then using the production work to illustrate it...there is a strong argument for using practical work deductively, as a means of generating fresh theoretical ideas" (2003, p.138). This is a laudable aim, and this chapter seeks ways of facilitating a comparable synthesis of theory and practice. It tends to be the case, however, that even at undergraduate level, the articulation of the term of relation between theory and practice tends to be awkward and there is often a sense that 'theory' is an unwelcome 'other' that has to be accommodated grudgingly in order to legitimate a piece of assessed work. 
Let's consider then the possible relationships between theory/writing and practice, and the debates about creative practice and research that are continuing in the academy. Through a discussion of the coordinates of these debates we seek to establish a more or less stable framework which will move us towards 'creative literacy'. Firstly we'll invoke Frayling's definitions of different kinds of research in the field of art and design; secondly we'll examine some ways of understanding the differences between knowledge and artefact; and thirdly we'll consider the possibilities of articulation without writing.

When Frayling (1993) uses three different prepositions to refer the relationship between research and art and design he is employing a deceptively simple strategy to reveal some profound distinctions. Firstly though, he is keen to assert the importance of research and theory in the everyday work of the artist, and debunks the "popular image of the fine artist as expressive lunatic [because it] does not allow sufficiently for the cognitive tradition in art - a tradition which has in fact been called 'research'. Nor does it allow for the fact that art happens in a social, technical and cultural world" (1993, p.4). Frayling proposes three ways of conceiving research in relation to art and design (by extension they are applicable to any form of creative practice): research into art and design; research through art and design; research for art and design. The first ('into') he describes as including historical research, aesthetic research, and research driven by particular theoretical perspectives. The second ('through') he describes as 'materials research', development work, and action research which documents, for example, a practical experiment. The documentation of the process is central to this definition: "Both the diary and the report are there to communicate the results, which is what separates research from the gathering of reference materials" (1993, p.5). The third ('for') he describes as being the most challenging: "Research where the end product is an artefact - where the thinking is, so to speak, embodied in the artefact, where the goal is not primarily communicable knowledge in the sense of verbal communication, but in the sense of visual or iconic or imagistic communication" $(1993, \mathrm{p5})$. These terms of relation represent different orientations towards practice and research and, although we recognise that there would be different degrees of sophistication, it is not unrealistic to suggest that students at all levels should be able to develop an understanding of what the purpose of an artefact is, or what it 'does'. At its simplest, we might ask if it 
expresses something, proves something, or merely copies something. It is perhaps the case that in much media production work these questions are often subordinate to a notion of 'success' that tends to be articulated through technical and aesthetic criteria applied to the finished product - a kind of 'aesthetic empiricism' (Currie, cited in Bell, 2006). As we illustrate below, the development of a critical vocabulary is a key attribute of this relationship with practice.

Developing a critical approach to the terms of relation between theory and practice, although without explicit reference to Frayling, Bell makes a distinction between the "art object" and the "knowledge object" in creative-practice-based research. He identifies "two polarities" in discourses about this kind of research: "a sub-positivist one" which applies the principles of empirical methodologies to creative work; and a "romanticist one.... which privileges the expressive over the cognitive" (2006, p.93). Finding both inadequate Bell notes that

One of the weaknesses of many of the media arts programmes which have emerged out of media studies, is that while they have offered students some experience of media production, they have been slow to embrace a project-based arts pedagogy which gives the formal critique a central role in the development of a student's creative abilities. Indeed, a commitment to make sense of work within a public cultural context and with reference to available modes of critical thinking is present in the best film and imaging programmes where the acquisition of technique and mastery of convention and form is balanced with the teaching practices of selfcriticism and public accountability. (Bell, 2006, p.86)

It is 'formal critique' that we advocate and demonstrate later in this chapter as a central principle of creative literacy - a formal critique that goes beyond aesthetic empiricism and which encompasses reflection, experience and emotion. As Bell suggests, "as teachers, we are concerned with assisting our students to develop their work and to understand it through its critical contextualisation and interrogation with a public culture" (Bell, 2006, p.86), but also to understand themselves and their processes.

Creative literacy should incorporate this kind of intra-subjective dialogue, this reflection upon different modalities of expression and different ways of knowing, 
being and performing. Cannon argues that even quite young children can demonstrate an understanding that may not be, and may not need to be, translated into written or spoken language:

... in traditional modes of composition, such as writing, we learn to see-saw between two particular modes: the abstract conception of an intended meaning and - with varying levels of skill and articulacy - its graphic transcription, performed largely in isolation. Film-making is an alternative 'writing' stage that operates with inclusive, social and embodied practices with no loss of sophisticated intellectual investment. (Cannon, 2015, p.158)

Here Cannon identifies a kind of embodied knowledge that both Sennett (2009) and Crawford (2009) celebrate as a key attribute of craft. Crawford, for example, criticises a conception of "universal knowledge" which takes "no account of embodiment and purposiveness, those features of actual thinkers who are always in particular situations" (p.163). Sennett, similarly, recognises the value of "the constant interplay between tacit knowledge and self-conscious awareness" from which "craft quality" emerges (p.50). For Kress and Van Leeuwen too, the nature of production is such that "Content as well as expression will be developed into more abstract, more explicit and more systematic forms of knowledge" (Kress \& Van Leeuwen, 2001. p.79) suggesting that creative practice involves different modes of communicating and ways of knowing. What will continue to be a site of conflict and debate, however, is the nature and mode of the articulation of that "self-conscious awareness", or as Moon puts it, "the representation of that learning" (2004, p.14). To involve students in this discourse, or meta discourse in that it involves discussing the ways in which they articulate their own learning, is characteristic of how we understand creative literacy. And given that this understanding is oriented towards creative practice we find it useful to invoke Heidegger's interpretation of the Greek term technē which, he argued, despite the application of the word to both craft and art, actually denotes "a mode of knowing" (1993, p.184). For Heidegger, the revelation of knowledge facilitated by and about modern technologies and the way they are constantly transforming that knowledge - what he terms the "challengingforth" (Heidegger, 1977.p.296-7) is exactly the sort of critical interrogation we argue should be at the heart of creative practice and is essential for Creative Literacy. We 
would also argue here that in his discussion of technē, Heidegger makes a connection between this mode of knowing and artisan labour (1977, p.294), allowing us to see craft skills as being central to this view of creative practice.

In the discussion that follows it will be evident that we are attempting to do two things: to identify opportunities for identifying, recognising and valuing creative literacy; and secondly to consider some strategies for nurturing and generating this kind of critical, conscious orientation to practice. A pedagogic model for this kind of work is, as Bell suggests, likely to draw on ethnography, perhaps even auto ethnography, in that, at higher levels, it requires students to reflect upon their own identities as practitioners and to address their investment in such things as 'creativity'.

\section{Creative Literacy in Practice}

The notion of a 'creative literacy' that might be characterised by a set of critical attributes which students use to interrogate their own production processes, arises out of a need to understand the clear connection between creative practice and criticality that exists in media education. Connolly (2013b) has argued that creative production is the engine of critical learning, in that it drives students on by giving them the opportunity to explore, try out and experiment with the critical concepts that they have learnt in class. This process is cyclical, with students learning to reflect upon what they have made in terms of those critical concepts and then utilising that reflection further when they make new media products. This process, characterised by Connolly as one of synthesis, involves the student critically interrogating not only what they have made, but also what they have learnt through the production process. This philosophically reflective and reflexive orientation towards production is characterised by a number of critical attributes, which we can identify as forming the basis for a creative literacy. These attributes are illustrated here by the activity of four students - here labelled $A, B, C$ and $D$ who were working on a range of moving image media production projects over a three year period (Connolly 2013b;pp5-8) . The four students all submitted a number of video projects as part of qualifications in Media Studies over this time. Two of the students referred to here are female (A\&B) and two are male (C\&D) and were aged between 15 and 18 years of age when the projects took place. They were all students at a large (1800 
pupil) Secondary school on the edge of London. The attributes can be summarised as follows:

\section{A highly developed level of control over what Kress and Van Leeuwen} (Kress \& Van Leewuen; 2001) term the "strata" of design and production

For the creatively literate media student, choices about the modes of communication (design) and the way that the medium chosen to manipulate those modes is used (production) will be given careful critical consideration. Those choices will be made in order to deliver a particular critical discourse (to use another of Kress \& Van Leeuwen's terms). Discourse here, is defined as a "socially constructed knowledge of some aspect of reality" (Kress \& Van Leeuwen, 2001; p.4). They are quite clear that this knowledge can appear in any number of modes For example, Student $A$ is making a film trailer for a romantic comedy (in this example, both romance and comedy might be examples of discourses that are being critically examined through the creative practice) and to do so, rearranges her parents' living room in order to make it look like a bedroom belonging to a wealthy "princess" type character. She does this in order to create a sense of scale that she cannot create in any of the other rooms in her house. She dresses the set, making the living room look like an authentic opulent bedroom, prepares an actor and then shoots and edits the scene in such a way that the scale of the room and its suitability for a spoilt rich girl become clear (Connolly, 2013; p135-136). Here, then the student has made multiple decisions about design modes (mise-en-scène, movement, gesture, camera) and production (editing the scene together) to deliver a particular discourse about a particular kind of female behaviour

\section{A set of craft skills which generate a critical vocabulary}

The craft skills used in production work, such as camerawork or digital editing, are a realisation of this level of control in the critical choices made about mode and medium; the creatively literate student will also be able to talk about both these choices and the craft skills used through the development of a critical vocabulary which makes sense of the way that the production shows conceptual understanding, while at the same pointing towards the way that conceptual understandings might be 
explored in future production work. The interplay between these craft skills and critical vocabulary will develop over time as students become familiar with both and take ownership of them. For example, Student B develops her conceptual knowledge of camerawork and editing through the craft skill of digital editing. In a relatively early stage of her development, she appears tentative about the critical vocabulary and its relationship to the craft skill of editing; when evaluating her work, she comments on the editing process, this unfamiliarity is hinted at when all the technical and conceptual vocabulary appears written in inverted commas:

We then dragged the footage on to the 'timeline' and began looking through the footage and using the 'razor' tool, we cut up the footage and re-arranged the shots. Then we deleted the ones which had laughing, smiling, bad camera work etc.

She is attempting here to produce what Connolly has termed the "orthodoxy" of the critical vocabulary that the teacher wants her to be familiar with . The presentation of construction concepts such as "timeline" and "razor", using inverted commas, suggests a developing ownership of these critical concepts alongside a clear understanding that that the broad concept of editing is about cutting up and rearranging. Knowledge of the concept here is being revealed through the technē of editing.

\section{A tendency to see play and experimentation with both technology and concepts as integral to the production process}

Play here might be seen both in the Vygotskyan sense of imaginative acts, as well as in the more physical sense of playing with a toy or game. The development of a particular set of technē skills (Connolly, 2013; Connolly, 2014) in editing digital video, or photo editing allow the creatively literate individual to exploit the affordances of digital technology in such a way that play becomes about the development of criticality. The student picks up and puts down the digital tools - razor, crop, eraser with a click of the mouse, and this allows them to do something similar with the concepts that that they are learning - continuity editing, narrative structure - playing with them and rearranging them until their understanding is clear. As a consequence, 
what sometimes may seem to the outside observer as "messing around" is actually an important part of becoming creatively literate. Connolly (2014) has given accounts of this phenomenon previously and points towards this distancing - using inverted commas, describing the production process as "messing around," demonstrating something playful about the work that students are doing, not only in the sense of having fun, but also in the sense of playing around with the concepts and what they mean. It can also be read as indicative of a meta discursive mode, in which students comment implicitly on their own understanding of, or perhaps playful engagement with, modes of address and language.

\section{An understanding of the importance of collaboration}

A creatively literate student will often seek to collaborate in order to work through unfamiliar concepts, but will also use creative collaboration as a way of carrying out the kind of play and experimental acts identified in the paragraph above. In the formation of concepts, it is clear that the students here are developing their ideas and becoming critically and conceptually literate by reaching a consensus on those meanings with their classmates. Student B describes this process of reaching her consensus with her group with regard to editing the group project, with the word "contemplate" here used alongside a critical vocabulary (fade, cut) in a way that intimates a reflexivity achieved through collaborative effort:

In most of the sequence we used just the ordinary cut as it was most effective, but we also used the fade to white when the "attacker" flashed up onto the screen. We contemplated using black instead of a white flash but the white made it more dramatic.

Such group collaboration is part of the creative engine that drives learning, and as such, can be seen as a mechanism for dealing with unfamiliar concepts. This can occur either in the formal group work setting or through more informal collaborations with others.

\section{The ability to synthesise or articulate the different kinds of learning that have gone on in the creative process}


Synthesis here describes the way that the student brings together both personal cultural and conceptual knowledge and the new unfamiliar knowledge introduced to them through the teaching process, in their production work. In Connolly's model of learning progression (Connolly, 2013b) which seeks to describe the way learning works, this is a cyclical process, wherein unfamiliar texts become newly familiar and unfamiliar concepts become accustomed ways of thinking and analysing. Connolly's "dialectic of familiarity" metaphor here identifies two distinct stages in which separate syntheses occur at different points. The first point of synthesis when a student begins to demonstrate a clear understanding of broadly orthodox critical views and cultural texts. This synthesis then becomes basis for a fuller, more expansive - to use Engestrom's term (Engestrom, 1999, p.7) - synthesis. The critical stage between one synthesis and the other is characterised by defamiliarisation, where the student can step back and critically analyse what they have made in the light of the conceptual knowledge and cultural experiences that they have acquired, and then subsequently articulate how and why they did that. These kind of ontological and epistemological questions - "What is this thing that I have made?" or "What does this thing show that I know?" support Buckingham's notion of production work as deductive process and use the production work itself as a means of generating new ideas and the search for new texts to explore and new theoretical explanations for those texts.

\section{Inferences and interferences}

The examples of student work cited above suggest that the attributes identified are developed as much through the students own explorations of texts and technologies as they are by the input of the person teaching them. However, these examples imply some particular kinds of pedagogical activity as being integral to the development of the creative literacy achieved. The nature of what a practitioner does in his or her classroom to promote certain kinds of creative activity is often difficult pin down and operationalise, but we suggest that there are particular strategies that can be employed to bring about the necessary conditions of possibility. A number of accounts of creative pedagogy in its most general, "across the curriculum" sense have been offered (Wyse, 2012), but for media education and literacy there are very few analyses of what the media teacher actually does in 
pedagogical terms and even fewer which deal with the question of what a creative pedagogy for media education might look like. (Buckingham, 2003, pp.70-85; McDougall, 2006; Domaille, 2012, pp.225-239) ). We would suggest that the critical attributes outlined above, however, proffer some kind of insight into the kind of teaching that needs to go on for students to become creative in their use of media texts and acquire the philosophically grounded approach to production that we have discussed. These pedagogic practices can be characterised through four broad themes and we deal with each in turn below:

- $\quad$ Exploring and making use of media texts

- $\quad$ Encouraging the adoption of a critical vocabulary

- $\quad$ Teaching the Technology

- $\quad$ Working in Groups

\section{Exploring and making use of media texts}

In order for students to demonstrate a high level of control over things like production and design - and develop an appropriate critical vocabulary with which to talk about those things - students need to be able to explore and make use of both familiar and unfamiliar texts. Connolly (2013; p.119) has explained that one of the key elements of learning progression is the opportunity that the student is given to reframe their experience of popular cultural texts in light of pedagogical input. Effectively, teachers either introduce students to entirely new kinds of text, or they encourage students to think about them in new ways. This process of defamiliarising, to use Connolly's term is effectively a means of prescribing academic capital to cultural capital and as such students end up placing a new kind of value on these texts and ideas, often beginning to see themselves as having multiple identities as producer, consumer student and even agitator.

For example, Student B, for a GCSE Media unit of work on documentary, creates a spoof wildlife documentary, which illustrates knowledge of a wide range of texts through its production. In the documentary, a student takes the role of presenter, and facing the camera, holds a pencil case case as if it were a prehistoric artefact. This is part of a number of discourses within not only the documentary genre (a genre which often looks to make the everyday surprising to us) but also about school and the 
territorial nature of student's possessions. This is a funny scene, because it comments on both the genre of documentary and schools themselves, while at the same time being technically very proficient. The discourse here is more complex than it looks. There is a connection made between documentary and the professorial nature of the people who tend to present them, as well as the implicit comment that schools are wild places which seem like metaphorical jungles to outsiders. The decisions taken to make the documentary in this very multi-layered and polysemic way, such as the choice of a "bookish" student to present and the mixture of close-up and medium close-up shots, to frame him, David Attenborough-style against the background of his subject indicate, again a great deal of thought. These design decisions both explore and foreground a range of abstract concepts, such as documentary, parody and authority, but they do it in such a way that they are very firmly rooted in the imagination of the student. The technē here - revealing knowledge of both the concept of the documentary and the culture of school through the craft skills of camerawork and scriptwriting - goes beyond the mechanistic exercise of just making something and is being used to do something genuinely creative.

For a teacher to generate an environment conducive to becoming creatively literate then, they must see the students' experience of popular culture as an essential pedagogical too and encourage them to use that wherever possible. All too often it is the case that students have extensive cultural capital which is never validated in the media classroom because teachers have no understanding of it (or are, perhaps fearful of it) and as such cannot press it into service. They must also be prepared to consider that students will make use of texts that they have been introduced to in ways that the teacher is not expecting, such as the parody described above. This requires a degree of pedagogic de-centring - what Bennett et al. call "a pedagogy of the inexpert...neither a tidy nor a literal concept, but...a rhetorical provocation to the traditional model of the teacher as 'subject expert"' (p.231).

\section{Encouraging the Adoption of a critical vocabulary}

The kind of philosophical reflexivity that was demonstrated by Student B in discussing the decisions she made about her, and her group's, choice of editing transition owes something to the explicit teaching of a range of technical terms $-a$ 
critical vocabulary or metalanguage, and the associated conceptual knowledge that accompanies them. The pedagogy that allows for this metalanguage to develop can be seen at one level as being about instruction, but at a deeper and more significant level, as being about an exploration of the conceptual through the creative production process. It is important for the teacher to make a distinction, at least in her own mind, about the distinction between the critical and the conceptual: "Critical" is what the teacher, wants students to "be"; that is, able to discuss in detail and show through their production work, the way a text works and creates meaning, including the way that certain concepts such as audience and institution influence that meaning. The "conceptual", on the other hand is a set of ideas that the student uses to become critical. The best way of viewing these conceptual understandings is as a set of tools for organising the student's ability to understand and become critical in the text that they are studying and/or making. The necessity for a critical vocabulary or metalanguage with which to discuss the way these conceptual understandings are manifested in the students' creative production work is something that may, initially, be introduced and reinforced by teachers through direct instruction or through correcting errors and misunderstandings in its use. The following exchange between student $C$ and his teacher in discussing a piece of film work he has made illustrates how this might take place

Student C: We watched Vertigo and got this idea for a forward tracking zoom out shot thing....

Teacher: Forward tracking zoom out?

Student C: Reverse tracking zoom out....

Teacher: Huh?

Student C: It's the Jaws shot, kind of thing... where he looks down but the scenery appears to move forward.

Teacher: Yes... that's sometimes called a contra-zoom.

Student $C$ : Yes, all that really is, is pushing the camera forward and zooming out. 
However, the real exploration of this critical vocabulary comes sometime later when asked about another film project completed some 9 months after the one discussed above he describes what he could have done to improve his work;

... if I'd had copious amounts of room, I would have done a $360^{\circ}$ pan as she was writing and try to get all the focus on the screen, and maybe get in an over the shoulder shot...(You learn about) those things in Media and after analyzing it, you learn that people will be watching it, and picking up on those things.

The pedagogic process here emphasises both the critical vocabulary here $\left(360^{\circ}\right.$ pan, over the shoulder) and the conceptual understandings that they describe - in this case the concept of audiences, be they the casual viewer, teacher or moderator. This combination of both conceptual understanding and use of metalanguage allows for both the ontological and epistemological interrogation that we believe is characteristic of creative literacy, as well as the development of a kind of selfreflexive awareness. This in turn, allows for the sort of philosophically orientated connections to be made between theory and practice which are vital to learning.

\section{Teaching the Technology}

It would seem that in the establishment of these creatively literate practices the role of the teacher is perhaps both multi-faceted and opaque. Sometimes, teaching students about the digital technology they need to use can involve the kind of direct instruction outlined above, but more often than not, this is only a small part of the pedagogic activity involved. The high level of control of both the strata of design and production, along with the development of the metalanguage demonstrated by creatively literate students might suggest we see the role of the teacher in a classroom where the students are manipulating digital video as a minimal one. Indeed, the nature of learning is bound to be scrutinized here and elsewhere, (Connolly, 2013, p.45) we have suggested that the ideas of Lave and Wenger become important (Lave and Wenger, 1991). Their concept of "peripheral participation" (1991, p.29) wherein learners do not acquire knowledge simply through what is instructed, but also through what occurs on the periphery of instruction what John Seeley Brown calls "stealing knowledge." (Seeley-Brown and Duguid, 
2000, p.245) In the media classroom this can very easily occur by watching others and the way they make and talk about moving image texts. In such an environment then, using digital technology could be equally about what the teacher isn't doing as much as it is about what they are doing.

However, while this might imply that the student may have the upper hand on the teacher in terms of using the digital technology, the student needs to make sense of the way that the technology might be used to order and re-order their experience of the world. We want to argue that the teacher "re-points" the student's skills with digital technology towards those texts and practices that they are not familiar with, in order to make sense of them, and to use the technology as an interrogative tool that allows them to reflect on what they know of the concepts they are exploring in their production work. This is demonstrated in the way that Student $D$ talks about a music documentary production he has completed.

Sound issues also occurred, but considering the room we had to interview in, there was not much I could do to reduce echo or ambience. In general, I feel the sound quality came out very well. Plus, any ambience or other feedback is drowned out by the mp3 track layered underneath the speech audio track. The final problem I encountered with performing this interview, were people on the tour walking around, packing equipment away and slamming doors. This was all picked up on the camera microphones, however, with the audio mastering tools on Sony Vegas, I was able to reduce levels and raise others to effectively remove these aggravations.

Here, Student D's conceptual knowledge of both genre (music documentary) and audience are being interrogated by a reflection upon the process of digitally editing the text together. The developed craft skill of editing is being used by Student $D$ to self-assess his own understanding of these concepts (Is this good enough for my audience? Will they accept it as a music documentary?) through both a use of the critical vocabulary he has learnt (ambience, echo, feedback) and a defamiliarisation of the product he has made. We would argue that this creatively literate reflection is a consequence of a pedagogy which uses instruction, demonstration, and peripheral participation, but ultimately rests upon the way that the teacher can assist the student in using the technology to facilitate conceptual understanding. 


\section{Working in Groups}

A final inference that can be made here about the kind of pedagogy that is associated with the development of a creative literacy refers to the way that teachers manage and encourage students when they work in groups. Numerous theorists (Buckingham,1995 \& 2003; Sefton-Green, 1995; Grahame, 1990) have emphasised the importance of group work in creative production, but we would argue that collaboration is an essential pedagogical tool in moving students towards a creative literacy. Encouraging students to work together and take different roles is integral to understanding how learning takes place through production work (Connolly, 2013) but for some students offering the opportunity to lead and marshal groups is a key way of developing the kind of creative competencies we are arguing for here.

Student B, for example shows that her creative skill lies in knowing how to marshal people - and not simply actors, but rather anybody involved in the collaboration of the productions. For example, in the shot from one of her film projects - in this case a short horror movie - selected below, it is worth considering what she has done with the main character in the sequence. In the shot, (Fig.1) the central character has tripped while trying to escape an assailant. This fall has an air of authenticity about it, which, in itself, is a not inconsiderable effect to achieve with an amateur actor who needs to put themselves in harm's way to complete the shot but Student B (and presumably other people in the group) have made her feel comfortable enough to do it. It is fairly reasonable to assume that this is unfamiliar territory for both actor and director but they know that to demonstrate their knowledge of the (familiar) genre and their technical proficiency, they need to engage in this sort of activity. Analysing the gesture and movement here - in an echo of Marcalo's (2009) ideas about the articulation of knowledge - suggest that the action (of falling over or being tripped) is also linked to critical understanding here though, in that either the action is included to demonstrate the high angle shot, or the high angle shot has been included to highlight the action of the fall and communicate a specific meaning by combining the mo

de of movement with mode of camerawork. 


\begin{tabular}{|l|l|l|l|}
\hline Fig. 1 & Shot & HA \\
\hline \multirow{n}{*}{} & Dialogue & None \\
\cline { 3 - 4 } & Movement & $\begin{array}{l}\text { Victim has } \\
\text { tripped after } \\
\text { being chased by } \\
\text { her stalker }\end{array}$ \\
\cline { 3 - 4 } & Location & $\begin{array}{l}\text { outside school } \\
\text { gates }\end{array}$ \\
\cline { 3 - 4 } & Music & $\begin{array}{l}\text { Untitled "creepy } \\
\text { electronic music }\end{array}$ \\
\hline
\end{tabular}

For Student B, the collaborations involved in this projects, leads not only to an increase in her conscious engagement with her creative practice, but also that of others, as they learn about the imaginative transformation of semiotic tools into concepts by being involved in what the group does. This kind of direction then, is a creative literacy that facilitates the creative literacy of others, who act, speak and move in ways that they probably would not do were the group not working in this way, The teacher's ability to facilitate this kind of "risky" group work (designating a leader, letting them work outside the classroom, assessing what or what not might involve seeking permission from the teacher) allows Student $B$ to be able to ask a greater range of epistemic questions about the text, as evidenced by her comments from the discussion that she and her group had about cutting and fading this particular sequence.

\section{Conclusions}

We have outlined our own resistance to some key terms that are often mobilised in the context of media education and gone on to describe a conceptual framework for production work which draws on debates around practice as research - a framework we call 'creative literacy'. We have then discussed some examples of what creative 
literacy might look like in action and how it might be apprehended and understood. We now finish by summing up some principles and practices that may develop and enrich this orientation to practice.

We suggest that explicitness of intention is fundamental: educators must be clear about the purpose of a piece of work and be able to communicate this to students. It may be a simple technical exercise designed to hone a particular skill, or it may be open brief in which originality and imagination are sought - we must be able to answer the question "what's the point?"

When providing feedback on work we must stick to the terms established at the beginning - it is not reasonable to 'hijack' feedback with a different category of feedback (although one would hope that the creatively literate student would challenge this).

Opportunities for reflection should be provided - opportunities that should elicit more than the token 'evaluation' of who did most/least in a group, and an anxiously positive spin on feedback from audiences.

There should be encouragement to articulate ontological and epistemological questions in relation to students' own work: "what does this piece of work say/do?"; "what roles did I adopt in its execution?"; "how do I feel about them?"

And ultimately, of course, we should subject ourselves to the same scrutiny as, we hope, creatively literate practitioners/educators: what are our own assumptions about 'creativity'? What do we think is the purpose of production work? Are we prepared to engage openly in this discussion?

\section{References:}

Bennett, P., Kendall, A. and McDougall, J., 2011. After the Media: Culture and Identity in the 21st Century. Abingdon: Routledge.

Boden, M., 1992. The Creative Mind. London: Abacus. 
Bruce, B., 2002. Diversity and Critical Social Engagement: How changing technologies enable new modes of literacy in changing circumstances. In Alvermann D., ed. Adolescents and Literacies in a Digital World. New York: Peter Lang.

Buckingham, D., 2003. Media Education: Literacy, Learning and Contemporary Culture. Cambridge: Polity Press.

Buckingham, D., J. Grahame and Sefton-Green, J., 1995. Making Media: Practical Production in Media Education. London: English and Media Centre.

Burn, A. and Durran, J., 2007. Media Literacy in Schools: Practice, Production and Progression. London: Paul Chapman Publishing.

Cannon, M., 2016. Media-making matters: Exploring literacy with young learners as media crafting, critique and artistry. (PhD). Bournemouth University.

Connolly, S., 2014. 21st Century Artisans: Creativity, Craft and Techne in Digital Video Production. Media Education Research Journal. 5 (1), (pp.32-45)

Connolly, S . 2013a "Media Education: A tool for Social Inclusion" in: Fraser, P., and Wardle, J., eds. Current Perspectives in Media Education: Beyond the Manifesto. Basingstoke: Palgrave Macmillan, pp.160-174.

Connolly, S. 2013b. Learning Progression in Secondary Digital Video Production. $\mathrm{PhD}$ Thesis. London. Institute of Education

Craft, A., 2001. 'Little c Creativity'. In: Craft, A., Jeffrey, B., and Leibling, M., eds. Creativity in Education. London: Continuum.

Crawford, M. B., 2010. Shop class as soulcraft: An inquiry into the value of work. New York: Penguin.

Domaille, K., 2012. Professional Preparation, Progression and Development of Media Teachers. In. Scarratt, E. \& Davison, J., eds. The Media Teacher's Handbook, London: Routledge, pp. 225-240.

Engestrom, Y., 1987. Learning by Expanding: An Activity-theoretical Approach to Developmental Research .Orienta-Konsultit Oy.Helsinki

Grahame, J., 1990. Playtime: Learning about Media Institutions through practical work. In Buckingham D., ed. Watching Media Learning. London: Falmer Press.

Heidegger, M., 1977. The Question Concerning Technology. In: Krell, D. F., ed. Martin Heidegger: Basic Writings. New York: Harper Collins, pp.294-297

Heidegger, M., 1993. The Origin of the Work of Art. In: Krell, D. F., ed. Martin Heidegger: Basic Writings. London: Routledge, pp.143-212. 
Hoechsmann, M. and Poyntz, S.R., 2012. Media literacies: A critical introduction. Malden, MA: Wiley-Blackwell.

Jenkins, H., 2008. Convergence Culture: Where Old and New Media Collide, New York: New York University Press.

Kalantzis, M. and Cope, B., eds. 1999. Multiliteracies: Literacy learning and the design of social futures. London: Taylor \& Francis.

Kress, G. and Van Leeuwen, T., 2001. Multimodal Discourse: The Modes and Media of Contemporary Communication. London: Arnold.

Lave, J. and Wenger, E., 1991. Situated Learning: Legitimate Peripheral

Participation. Cambridge: Cambridge University Press.

Luke, C. 2004. Re-crafting Media and ICT Literacies. In: Alvermann D., ed.

Adolescents and Literacies in a Digital World.: New York: Peter Lang.

Marcalo, R. 2009. Failing to do without: Writing as classical documentation of postclassical choreographic documentation. Journal of Writing in Creative Practice, 2 (1), pp.105-116).

McDougall, J., 2006. The Media Teacher's Book. London: Hodder Arnold.

McRobbie, A., 2016. Be Creative: Making a Living in the New Culture Industries.

Cambridge: Polity Press.

Moon, J., 2004. A Handbook of Reflective and Experiential Learning: Theory and Practice. Abingdon: RoutledgeFalmer.

Nelmes, J., 2007. Some thoughts on analysing the screenplay, the process of screenplay writing and the balance between craft and creativity. Journal of Media Practice, 8 (2), pp.107-113.

Ong, W.J., 1982. Orality and literacy: The technologizing of the word. 2nd ed. New York: Methuen.

Readman, M., 2009. Don't mention the 'c word': The rhetorics of creativity in the Roberts Report. Networks, 07, pp.8-9.

Readman, M., 2010. What's in a word?: The discursive construction of 'creativity'. (PhD). Bournemouth University.

Readman, M., 2011. Inspecting creativity: Making the abstract visible. Media Education Research Journal, 2 (1), pp.57-72.

Readman, M., 2013. Not 'Philosophy of Media Education', but 'Media Education as Philosophy': Working with 'Creativity'. In: Fraser, P., and Wardle, J., eds. Current Perspectives in Media Education: Beyond the Manifesto. Basingstoke: Palgrave Macmillan, 
pp.160-174.

Seeley-Brown, J. and Duguid, P., 2000. The Social Life of Information. Cambridge: Harvard Business School Press.

Sefton-Green, J., 1995. "New Models for Old" in Making Media: Practical Production inMedia Education. Buckingham, D., Sefton-Green J. and Grahame, J. London. English and Media Centre.

Sennett, R., 2008. The Craftsman. London: Penguin.

Woods, P., 2001. Creative Literacy. In: Craft, A., Jeffrey, B., and Leibling, M., eds. Creativity in Education. London: Continuum, pp.62-79.

Wyse, D., Baumfield, V., Egan, D., Gallagher, C., Hayward, L,. Hulme, M., Leitch, R., Lingard, B., Livingston, K. \& Menter, I. 2013., Creating the curriculum. London: Routledge 